\title{
PENGEMBANGAN E-LEARNING MELALUI MODUL INTERAKTIF BERBASIS LEARNING CONTENT DEVELOPMENT SYSTEM
}

\author{
Heni Rodiawati ${ }^{1}$ \& Komarudin ${ }^{2}$ \\ 1,2 UIN Raden Intan Lampung, Bandar Lampung/Lampung, Indonesia \\ 1henirodiawati99@gmail.com, 22qhomar8@gmail.com
}

\begin{abstract}
Abstrak
Penelitian ini bertujuan untuk menghasilkan bahan ajar berupa e-learning yang melalui modul interaktif berbasis learning content development system pada materi bangun ruang sisi datar. Metode penelitian ini adalah Research and Development (R\&D) berdasarkan model Sugiyono yang membatasi menjadi 7 langkah yaitu potensi dan masalah, mengumpulkan informasi, desain produk, validasi produk, revisi produk, uji coba produk dan revisi produk. Kelayakan modul interaktif berdasarkan ahli materi termasuk dalam kategori " Sangat Layak" dengan skor persentase sebesar $82,83 \%$. Penilaian ahli media terhadap modul interaktif ini termasuk dalam kategori "Sangat Layak" dengan skor persentase sebesar 82,625\%. Penilaian ahli bahasa terhadap media ini termasuk dalam kategori "Sangat Layak" dengan skor persentase sebesar 96\%. Pada uji coba skala kecil di SMPN 6 Kotabumi memperoleh skor persentase sebesar 85,625\%, di SMPN 11 Kotabumi memperoleh skor sebesar 87,71\%, dan di SMP Hang Tuah Kotabumi memperoleh skor sebesar $84,375 \%$, hasil ini menempatkan modul interaktif pada kriteria "Sangat Menarik". Pada uji coba skala besar di ketiga sekolah tersebut memperoleh skor sebesar 84,5\%, 89,61\%, dan 88,61\% dengan kriteria "Sangat Menarik".
\end{abstract}

Kata kunci:, Pengembangan E-Learning Matematika; Modul Interakktif; LCDS

\begin{abstract}
This study aims to produce teaching materials in the form of elearning mathematics through interactive module based learning content development system on the material of building a flat side space. This research method is research and development (R\&D) based on Sugiyono model that limits to 7 steps that are potential and problem, gather information, product design, product validation, product revision, product trial, and product revision. The feasibility of an interactive module based on a material expert is included in the "Very Decent" category with a percentage score of $82,83 \%$. The media expert's assessment of this interactive module belongs to the "Very Decent" category with a percentage score of $82,625 \%$. The assessment of linguists to the media is included in the "Very Decent" category with a percentage score of 96\%. In a small-scale trial at SMPN 6 Kotabumi it obtained a percentage score of 85,625\%, in SMPN 11 Kotabumi scored $87,71 \%$, and in SMP Hang Tuah Kotabumi scored 84,375\%, these results place an interactive module on the "Very Interesting"
\end{abstract}


Rodiawati, H., \& Komarudin, K. (2018). PENGEMBANGAN E-LEARNING MELALUI MODUL INTERAKTIF BERBASIS LEARNING CONTENT DEVELOPMENT SYSTEM. Jurnal Tatsqif, 16(2). Retrieved from http://journal.uinmataram.ac.id/index.php/tatsqif/article/view/190

criteria. In large-scale trials in the three schools scored $84,5 \%$, 89,61\%, dan 88,61\% with the criteria of "Very Interesting."

Keywords: Development of E-Learning Mathematics; Interactive Module; LCDS;

\section{PENDAHULUAN}

Pendidikan merupakan kebutuhan yang sangat penting bagi kehidupan setiap manusia. Sebab pendidikan adalah usaha sadar dan terencana yang dilakukan untuk mengembangkan potensi yang ada dalam dirinya sendiri untuk mengembangkan kemampuan berpikir, akhlak, pengetahuan, kepribadian dan spiritual agama untuk kebutuhan mereka di masyarakat. Pendidikan memberikan pengaruh yang besar dalam kehidupan manusia untuk memajukan kehidupan suatu bangsa.

Memajukan suatu kehidupan bangsa salah satu yang dapat dilakukan yaitu dengan meningkatkan perkembangan pendidikan. Hal yang mempengaruhi perkembangan pendidikan adalah pendidik. Hal tersebut karena pendidik lah yang memegang peranan penting dalam proses pembelajaran. Pendidik yang berkualiatas akan menghasilkan peserta didik yang berkualitas pula. Menurut (Mujib \& Mardiyah, 2017) hal lain yang mempengaruhi upaya meningkatkan mutu pendidikan dan kehidupan bangsa adalah matematika.

Matematika adalah salah satu pelajaran yang mampu mengembangkan kemampuan kreativitas dan menekankan pada pemecahan masalah. Namun menurut (Nurina, 2017) berpendapat bahwa masyarakat masih memandang tentang pelajaran matematika merupakan pelajaran yang sulit dan menakutkan. Oleh sebab itu diperlukannya suatu inovasi untuk mengubah pola pemikiran peserta didik untuk menyukai matematika. Hal yang dapat dilakukan yaitu dengan mengembangkan media pembelajaran untuk menarik perhatian peserta didik dan merangsang pemikirannya.

Media pembelajaran yang sering digunakan saat ini masih sebatas pada buku cetak, oleh sebab itu dibutuhkanlah pengembangan media 
Rodiawati, H., \& Komarudin, K. (2018). PENGEMBANGAN E-LEARNING MELALUI MODUL INTERAKTIF BERBASIS LEARNING CONTENT DEVELOPMENT SYSTEM. Jurnal Tatsqif, 16(2). Retrieved from http://journal.uinmataram.ac.id/index.php/tatsqif/article/view/190

pembelajaran yang sesuai dengan kemajuan teknologi dan informasi yang sedang berkembang. Perkembangan media pembelajaran yang sesuai dengan kemajuan ilmu pengetahuan dan teknologi saat ini salah satunya adalah media pembelajaran yang berupa E-Learning melalui modul interaktif.

E-Learning atau Electronic Learning (pembelajaran elektronik) diartikan sebagai pembelajaran yang menggunakan media elektronik, atau menjalin hubungan melalui media lektronik, dalam hal ini dapat berupa komputer. $E$ Learning sangat memudahkan pendidik untuk menyampaikan materi pembelajaran dan dengan tampilan menarik perhatian peserta didik untuk belajar matematika. Saat ini banyak sekali aplikasi yang diluncurkan seperti geogebra, microsoft powerpoint, mathematicha 7, adobe flash, macromedia flash, dll yang sudah bisa dimanfaatkan oleh pendidik (Rubhan Masykur, Nofrizal, dan Muhammad Syazali, 2017).

Salah satu software yang digunakan dalam pembuatan media pembelajaran adalah Learning Content Development System (LCDS). LCDS adalah aplikasi yang memadukan antara teks, animasi, video, game, quiz, dan lain-lain yang dapat diakses secara online. Pengoperasian software ini sangat mudah dan sederhana, sehingga peserta didik tidak akan merasa kesulitan dalam menjalankannya. Software ini belum banyak digunakan dalam dunia pendidikan dan belum diketahui oleh banyak orang. Produk yang dihasilkan oleh software ini adalah modul interaktif yang dapat diakses secara online.

Melihat masalah yang tertera di atas, maka penulis melihat perlu adanya suatu inovasi untuk mengembangkan media pembelajaran untuk menarik perhatian peserta didik dan mengubah pola pemikiran mereka untuk menyukai matematika. Untuk mengatasi permasalahan yang sudah dipaparkan sebelumnya, penulis berniat mengembangkan modul interaktif bebrasis LCDS dengan tujuan untuk meningkatkan minat belajar peserta didik.

Penerapan E-Learning tidak dapat dilakukan secara sembarangan, karena jika dilakukan dengan tidak tepat guna dapat berdampak negative 
Rodiawati, H., \& Komarudin, K. (2018). PENGEMBANGAN E-LEARNING MELALUI MODUL INTERAKTIF BERBASIS LEARNING CONTENT DEVELOPMENT SYSTEM. Jurnal Tatsqif, 16(2). Retrieved from http://journal.uinmataram.ac.id/index.php/tatsqif/article/view/190

bagi siswa. Dalam konteks pembelajaran matematika, Putrawangsa \& Hasanah (2018) menegaskan bahwa prinsip dasar dalam penggunaan teknologi digital (misalnya E-Learning) dalam pembelajaran matematika adalah teknologi tidak digunakan sebagai pengganti penggunaan pemahaman konseptual dan intuisi bermatematika, akan tetapi sebaliknya teknologi berperan untuk meningkatkan pemahaman konseptual siswa tentang ide matematika dan juga mengembangkan kemampuan intuisi siswa dalam bermatematika.

Mengembangkan media pembelajaran matematika berupa modul pernah dilakukan sebelumnya dengan menggunakan aplikasi geogebra (Fiska, Farida \& Syazali, 2016), kemudian pengembangan media pembelajaran fisika dengan menggunakan aplikasi macromedia flash pro 8 (Eka, Yohanes \& Dwi Teguh, 2013). Namun penulis melakukan keterbaruan dalam penelitian ini yaitu dengan mengembangkan modul interaktif berbasis LCDS untuk meningkatkan belajar peserta didik dalam pelajaran matematika.

\section{LANDASAN TEORI}

Media pembelajaran yang umum digunakan beragam, seperti video pembelajaran, power point, dan lain sebagainya. Namun, masih banyak lagi media pembelajaran yang belum banyak digunakan dalam proses pembelajaran, salah satunya adalah Learning Content Development System (LCDS). Dalam dunia pendidikan masih belum banyak yang menggunakan aplikasi ini terutama untuk media pembelajaran matematika. Oleh sebab itu, peneliti berencana memberikan inovasi baru dalam pembelajaran matematika yaitu dengan membuat modul interaktif dengan menggunakan aplikasi LCDS. Media pembelajaran sesuai dengan kebutuhan, mencakup point-point penting dari materi yang dipelajari LCDS.

Menurut (Aremu \& Efuwape, 2013) menjelaskan pengertian LCDS yaitu The LCDS allows anyone in the microsoft training and certification community to publis e-learning courses and learning snacks by completing the easy-to-use 
Rodiawati, H., \& Komarudin, K. (2018). PENGEMBANGAN E-LEARNING MELALUI MODUL INTERAKTIF BERBASIS LEARNING CONTENT DEVELOPMENT SYSTEM. Jurnal Tatsqif, 16(2). Retrieved from http://journal.uinmataram.ac.id/index.php/tatsqif/article/view/190

LCDS forms that seamlessly generate highly cuztomized content, interactives, quizzes, games, assesments, animations, demos, and other multimedia.

Berdasarkan penjelasan di atas, dapat diketahui bahwa LCDS merupakan perangkat lunak yang mengkombinasikan dari hasil program lain yang memungkin setiap orang dalam komunitas atau organisasi tertentu untuk menerbitkan e-learning dengan menggunakan LCDS secara mudah dengan konten yang dapat disesuaikan, interactive activity, kuis, game, ujian, animasi, demo, dan multimedia lainnya. LCDS merupakan software yang memungkinkan kita untuk membuat konten yang berkualitas tinggi, interaktif, dan dapat diakses secara online.

Dalam membuat konten pada LCDS, terdapat langkah-langkahnya menurut (Dani \& Iqbal) yaitu sebagai berikut:

1. Create: pada tahap pertama, tentunya kita membuat kontent course/pelatihan. Menentukan tema, nama, struktur, dan jenis pelatihan. Pada LCDS telah tersedia template-template untuk setiap topik yang memudahkan kita dalam membuat konten e-learning yang berkualitas.

2. Preview: setelah kita memilih template yang sesuai dengan konten pelatihan dan mengisi template tersebut, kita dapat memprevies hasilnya. Hal ini memudahkan kita untuk tahu seperti apa hasil e-learning yang telah kita buat pada saat itu juga.

3. Refine: jika anda merasa kurang puas dengan konten maupun pemplatenya, anda dapat mengeditnya kembali dan kemudian menyimpannya.

4. Delight: publikasikan pelatihan anda dan mendistribusikannya kepada audiens melalui web atau learning management system.

Pengembangan E-Learning perlu memperhatikan fungsi dari E-Learning tersebut dalam pembelajaran agar dapat menjadi media yang dapat menudukung ketercapaian tujuan pembelajaran. Menurut Putrawangsa \& Hasanah (2018), terdapat tiga fungsi dedaktik dari teknologi dalam pembelajaran matematika, yaitu (1) teknologi digital yang berfungsi sebagai 
Rodiawati, H., \& Komarudin, K. (2018). PENGEMBANGAN E-LEARNING MELALUI MODUL INTERAKTIF BERBASIS LEARNING CONTENT DEVELOPMENT SYSTEM. Jurnal Tatsqif, 16(2). Retrieved from http://journal.uinmataram.ac.id/index.php/tatsqif/article/view/190

alternatif alat pengganti media kertas dan pensil untuk melakukan kegiatan bermatematika, (2) teknologi digital yang berfungsi sebagai lingkungan belajar untuk mengasah keterampilan matematika tertentu, dan (3) teknologi digital yang berfungsi sebagai lingkungan belajar untuk mengembangkan pemahaman konseptual tentang matematika. Dari ketiga fungsi dedaktik tersebut, teknologi digital yang berfungsi sebagai lingkungan belajar untuk mengembangkan pemahaman konseptual tentang matematika adalah hal yang tepat dalam penggunaan teknologi dalam pembelajaran matematika. Hal ini mengingat matematika sebagai sistem pengetahuan yang dibangun melalui suatu proses konstruksi pengetahuan dan pemahaman yang didapatkan dari pengalaman hidup, termasuk di dalamnya adalah pengalaman belajar (Putrawangsa \& Hasanah, 2018).

\section{METODE}

Metode penelitian ini adalah Research and Development (R\&D) berdasarkan model Sugiyono yang dibatasi menjadi 7 langkah yaitu (1) potensi dan masalah; (2) mengumpulkan informasi; (3) desain produk; (4) validasi produk; (5) revisi produk; (6) uji coba produk; dan (7) revisi produk (Sugiyono, 2014).

Subjek dalam penelitian dan pengembangan ini terdiri dari validasi ahli materi, media, dan bahasa, uji coba skala kecil dan uji coba skala besar. Validasi ahli materi dilakukan oleh dua orang dosen dan seorang pendidik. Untuk validasi ahli media dilakukan oleh dua orang dosen dan seorang guru dan validasi ahli bahasa dilakukan oleh seorang dosen. Uji coba produk dilakukan di SMPN 6 Kotabumi, SMPN 11 Kotabumi dan SMP Hang Tuah Kotabumi. Pada uji coba skala kecil dilakukan dengan 8 peserta didik dari masing-masing sekolah dan untuk uji coba skala besar dilakukan dengan 30 peserta didik.

Pada tahap validasi oleh para ahli, data diperoleh berdasarkan pengisian angket oleh para dosen dan pendidik dari masing-masing ahli di bidangnya untuk melihat kelayakan dari produk. Pada tahap uji coba skala kecil dan 
skala besar, data diperoleh melalui angket yang telah diisi oleh peserta didik untuk melihat respon peserta didik tentang kemenarikan dari produk.

Teknik analisis data dilakukan secara deskriptif. Analisis data pada instrument produk yang divalidasi adalah seperti memberikan skor pada setiap kriteria skala likert 4.

Hasil skor perhitungan disimpulkan dalam persentase dengan menggunakan rumus:

$$
P=\frac{\text { skor yang diobservasi }}{\text { skor yang diharapkan }} \times 100 \%
$$

Keterangan:

P: Persentase data angket

Setelah itu, hasil persentase angket yang diperoleh dari validasi produk dan uji coba produk dikategorikan berdasarkan interprestasi dalam tabel 1 dan 2 di bawah ini menurut (Suharsimi, 2014) sebagai berikut:

Tabel 1.

Kriteria Kelayakan

\begin{tabular}{cl}
\hline Skor Persentase & \multicolumn{1}{c}{ Heading } \\
\hline $80 \%<\mathrm{x} \leq 100 \%$ & Sangat Layak \\
$60 \%<\mathrm{x} \leq 80 \%$ & Layak \\
$40 \%<\mathrm{x} \leq 60 \%$ & Cukup Layak \\
$20 \%<\mathrm{x} \leq 40 \%$ & Kurang Layak \\
$0 \% \leq \mathrm{x} \leq 20 \%$ & Sangat Kurang Layak \\
\hline
\end{tabular}

Tabel 2.

Kriteria Kemenarikan

\begin{tabular}{cl}
\hline Skor Persentase & \multicolumn{1}{c}{ Heading } \\
\hline $80 \%<x \leq 100 \%$ & Sangat Menarik \\
$60 \%<x \leq 80 \%$ & Menarik \\
$40 \%<x \leq 60 \%$ & Cukup Menarik \\
$20 \%<x \leq 40 \%$ & Kurang Menarik \\
$0 \% \leq x \leq 20 \%$ & Sangat Kurang Menarik \\
\hline
\end{tabular}


Rodiawati, H., \& Komarudin, K. (2018). PENGEMBANGAN E-LEARNING MELALUI MODUL INTERAKTIF BERBASIS LEARNING CONTENT DEVELOPMENT SYSTEM. Jurnal Tatsqif, 16(2). Retrieved from http://journal.uinmataram.ac.id/index.php/tatsqif/article/view/190

Berdasarkan data yang terdapat pada tabel 2 di atas, pengembangan produk akan berakhir ketika skor penilaian pada tahap validasi dan uji coba modul interaktif telah memenuhi persyaratan kelayakan dan kemenarikan dengan tingkat kesesuaian kategori.

\section{HASIL DAN PEMBAHASAN}

Hasil utama dalam penelitian dan pengembangan ini adalah e-learning matematika yang melalui modul interaktif berbasis learning content development system pada materi bangun ruang sisi datar. Hasil dari setiap tahapan prosedur penelitian adalah sebagai berikut:

\section{Potensi dan Masalah}

Berdasarkan penelitian yang dilakukan di SMPN 6 Kotabumi, SMPN 11 Kotabumi, dan SMP Hang Tuah Kotabumi diperoleh informasi mengenai potensi yang terdapat pada sekolah tersebut yaitu terdapat laboratorium komputer yang memadai dan juga didukung dengan kemampuan di bidang komputer untuk pendidik dan peserta didik.

Masalah yang terdapat pada ketiga sekolah tersebut yaitu peserta didik kurang memperhatikan pendidik ketika mengajar dan juga bahan ajar yang digunakan masih sebatas buku cetak yang hanya dipegang oleh pendidik. Oleh karena itu, perlunya dikembangkan media pembelajaran yang sesuai dengan kemajuan tekhnologi seperti e-learning matematika melalui modul interaktif berbasis LCDS.

\section{Mengumpulkan Informasi}

Pada tahap ini peneliti mengumpulkan informasi mengenai pembuatan modul seperti SK, KD, Indikator dan juga referensi buku untuk mengembangkan materi yang akan digunakan. Kemudian peneliti mengumpulkan berbagai penelitian terdahulu untuk menjadi pembanding peneliti saat ini.

\section{Desain Produk}


Produk yang akan dibuat sebelum masuk dalam aplikasi LCDS, materi dibuat dengan menggunakan aplikasi powerpoint untuk tampilan yang menarik. Kemudian menggunakan aplikasi geogebra untuk membuat gambar dan animasi jaring-jaring yang dapat terlihat 3D. Aplikasi wonder share quiz creator untuk membuat soal evaluasi interaktif agar pendidik tidak perlu mengoreksi hasil pekerjaan peserta didik. Setelah materi, animasi, kuis interaktif, dll sudah selesai dibuat, maka langkah selanjutnya yaitu memasukkan satu persatu konten ke dalam aplikasi LCDS.

\section{Validasi Desain}

Validasi desain dilakukan oleh para ahli materi, ahli media, dan ahli bahasa. Ahli materi dilakukan oleh 2 orang dosen dan seorang pendidik yang menguasi di bidang materi tersebut. Ahli media dilakukan oleh 2 orang dosen dan seorang pendidik yang merupakan ahli dalam bidang komputer. Ahli bahasa dilakukan oleh seorang dosen yang merupakan ahli dalam sastra indonesia.

Berikut hasil validasi oleh ahli materi sebagai berikut:

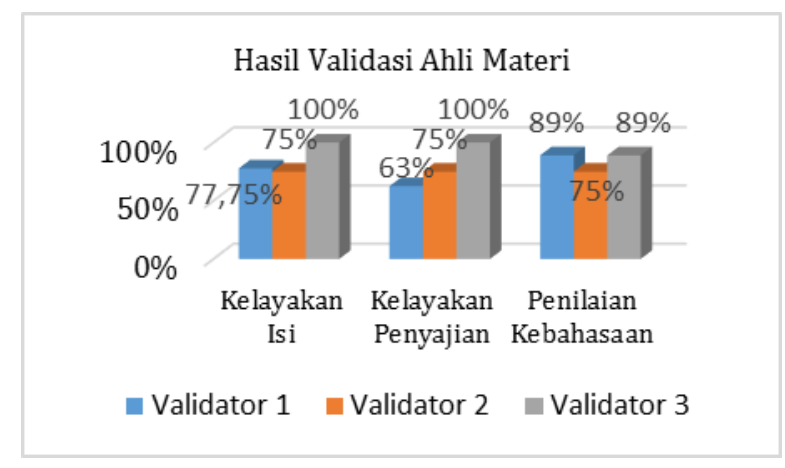

Grafik 1. Hasil Validasi Oleh Ahli Materi

Berdasarkan Gambar 1, diperoleh hasil kategori kelayakan isi oleh validator 1, validator 2 , dan validator 3 yaitu 77,75\%,75\%, dan 100\%. Untuk kelayakan penyajian diperoleh persentase sebesar 63\%, 75\%, dan 100\% dari masing-masing validator. Kemudian kategori penilaian kebahasaan diperoleh persentase sebesar 89\%, 75\%, dan 89\%. Berdasarkan penilaian ahli materi tersebut, maka modul dinyatakan "Sangat Layak". 
Berikut hasil validasi oleh para ahli media sebagai berikut:

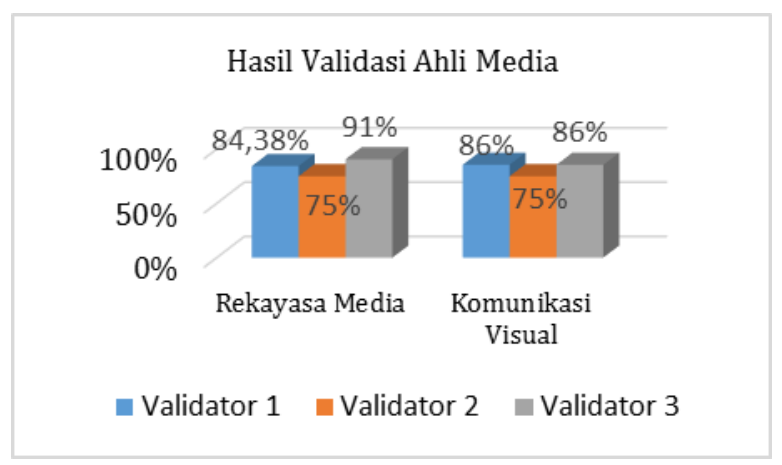

Grafik 2. Hasil Validasi Oleh Ahli Media

Berdasarkan Gambar 2, diperoleh hasil validasi oleh ahli media yaitu pada kategori rekayasa media diperoleh persentase sebesar 84,38\%, 75\%, dan 91\% dari masing-masing validator. Untuk kategori komunikasi visual diperoleh persentase sebesar 86\%, 75\%, dan 86\%. Berdasarkan persentase dari masing-masing kategori para ahli media maka modul dinyatakan "Sangat Layak".

Berikut hasil validasi oleh ahli bahasa sebagai berikut:

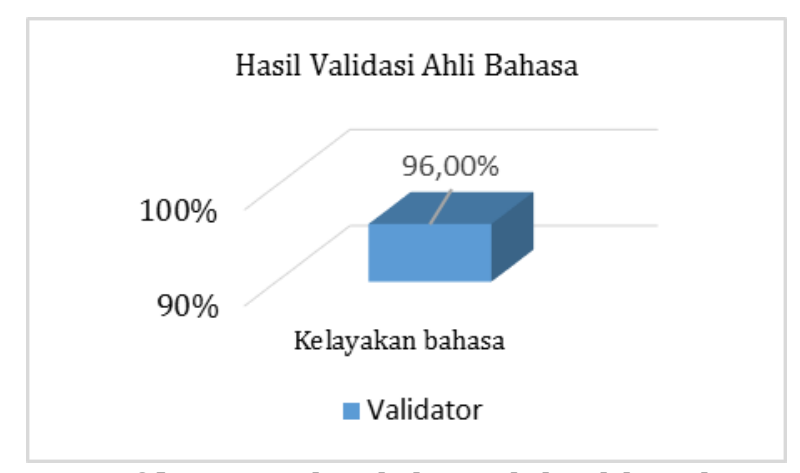

Grafik 3. Hasil Validasi Oleh Ahli Bahasa

Berdasarkan Gambar 3, diperoleh hasil validasi oleh ahli bahasa pada kategori kelayakan kebahasaan dengan persentase sebesa 96\% dengan kriteria "Sangat Layak".

\section{Revisi Produk}

Dari hasil validasi oleh ahli materi, ahli media, dan ahli bahasa, maka dilakukan revisi sesuai dengan saran dan komentar yang diberikan oleh pada validator. Berikut hasil revisi oleh ahli materi sebagai berikut: 
Tabel 3. Revisi oleh Ahli Materi

\begin{tabular}{|c|c|c|}
\hline No. & Saran Perbaikan & Perbaikan yang Dilakukan \\
\hline 1. & $\begin{array}{l}\text { Masukkan per konten } \\
\text { agar lebih menarik }\end{array}$ & $\begin{array}{l}\text { Memasukkan per konten sehingga modul } \\
\text { lebih efektif }\end{array}$ \\
\hline 2. & $\begin{array}{l}\text { Tambahkan gambar } \\
\text { pada contoh soal }\end{array}$ & $\begin{array}{l}\text { Menambahkan gambar pada setiap contoh } \\
\text { soal }\end{array}$ \\
\hline 3. & $\begin{array}{l}\text { Besarkan tulisan } \\
\text { sehingga tidak terfokus } \\
\text { pada background }\end{array}$ & $\begin{array}{l}\text { Memperbesar tulisan sehingga terfokus } \\
\text { pada tulisan }\end{array}$ \\
\hline
\end{tabular}

Para ahli media memberikan beberapa saran sebagai berikut:

Tabel 4. Revisi Ahli Media

\begin{tabular}{|c|c|c|}
\hline No. & Saran Perbaikan & Perbaikan yang Dilakukan \\
\hline 1. & Ubahlah ukuran modul & $\begin{array}{l}\text { Mengubah ukuran modul dari portrait } \\
\text { menjadi landscape }\end{array}$ \\
\hline 2. & $\begin{array}{l}\text { Buatlah kotak pada sisi } \\
\text { materi terlihat } \\
\text { transparan }\end{array}$ & $\begin{array}{l}\text { Mengubah kotak pada setiap isi materi } \\
\text { menjadi transparan terhadap background }\end{array}$ \\
\hline 3. & $\begin{array}{l}\text { Buatlah gambar } \\
\text { diagonal ruang tampak } \\
\text { atas }\end{array}$ & $\begin{array}{l}\text { Membuat gambar diagonal ruang yang } \\
\text { terlihat nampak dari aras }\end{array}$ \\
\hline
\end{tabular}

Berikut hasil revisi yang diberikan oleh ahli bahasa:

Tabel 5. Revisi Oleh Ahli Bahasa

\begin{tabular}{cll}
\hline No. Saran Perbaikan & \multicolumn{1}{c}{ Perbaikan yang Dilakukan } \\
\hline 1. $\begin{array}{l}\text { Perbaiki penulisan tanda } \\
\text { baca }\end{array}$ & $\begin{array}{l}\text { Memperbaiki penulisan dalam setiap } \\
\text { tanda baca } \\
\text { 2. Perbaiki kesalahan pada } \\
\text { penulisan }\end{array}$ & $\begin{array}{l}\text { Memperbaiki kesalahan yang terjadi } \\
\text { pada penulisan }\end{array}$ \\
\hline
\end{tabular}

\section{Uji Coba Produk}

Uji coba produk dilakukan di SMPN 6 Kotabumi, SMPN 11 Kotabumi, dan SMP Hang Tuah Kotabumi dengan tujuan untuk melihat respon peserta didik mengenai kemenarikan dari modul interaktif dengan menggunakan pengisian angket.

a. Uji coba skala kecil 
Uji coba skala kecil dilakukan dengan 8 peserta didik di masing-masing sekolah dengan penyebaran angket untuk melihat respon peserta didik terhadap modul interaktif. Berikut hasil uji coba skala kecil sebagai berikut:

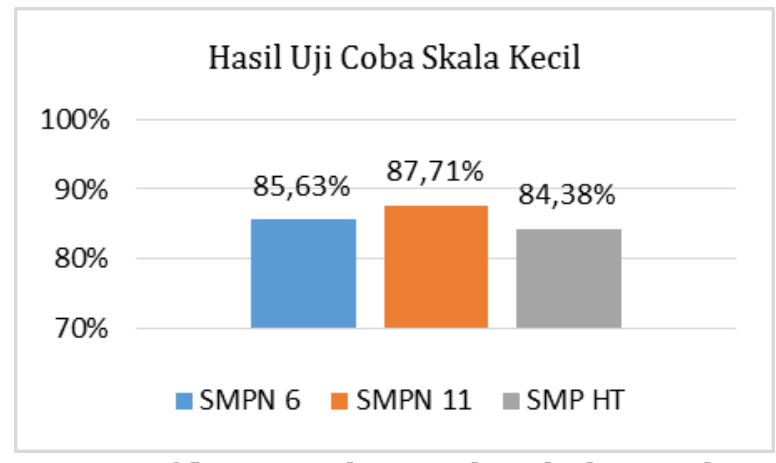

Grafik 4. Hasil Uji Coba Skala Kecil

Berdasarkan Gambar 4, diperoleh skor persentase yang menyatakan bahwa modul interaktif dalam kriteria "Sangat Menarik"

b. Uji coba Skala Besar

Uji coba skala besar dilakukan dengan 30 peserta didik dari masingmasing sekolah untuk melihat respon peserta didik terhadap modul interaktif. Berikut hasil uji coba skala besar sebagai berikut:

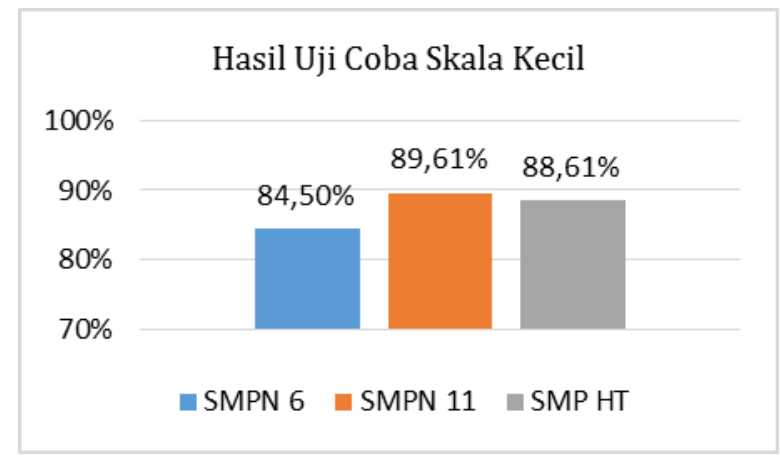

Grafik 5. Hasil Uji Coba Skala Besar

Berdasarkan Gambar 6, hasil persentase tersebut menunjukkan bahwa modul interaktif dalam kriteria "Sangat Menarik".

\section{Revisi Produk}

Setelah dilakukan uji coba skala kecil dan skala besar pada e-learning matematika melalui modul interaktif berbasis LCDS untuk melihat 
Rodiawati, H., \& Komarudin, K. (2018). PENGEMBANGAN E-LEARNING MELALUI MODUL INTERAKTIF BERBASIS LEARNING CONTENT DEVELOPMENT SYSTEM. Jurnal Tatsqif, 16(2). Retrieved from http://journal.uinmataram.ac.id/index.php/tatsqif/article/view/190

kemenarikan, produk telah dinyatakan dalam tingkat kemenarikan yang tinggi sehingga produk tidak perlu di revisi dan diuji coba ulang. Sehingga modul interaktif sudah dapat digunakan sebagai bahan ajar untuk proses pembelajaran dan menjadi referensi belajar dalam materi bangun ruang sisi datar.

\section{KESIMPULAN}

Berdasarkan teori dan didukung oleh hasil respon peserta didik serta mengarah pada perumusan maslah yang diuraikan, maka dapat disimpulkan bahwa e-learning matematika melalui modul interaktif berbasis LCDS yaitu "Sangat menarik" dari perhitungan skor rata-rata pada uji coba skala kecil yaitu 85,625\% di SMPN 6 Kotabumi, 87,71\% di SMPN 11 Kotabumi, dan 84,375\% di SMP Hang Tuah Kotabumi. Pada uji coba skala besar yang diikuti oleh 30 peserta didik skor rata-rata kemenarikan yang diperoleh yaitu 84,50\% di SMPN 6 Kotabumi, 89,61\% di SMPN 11 Kotabumi, dan 88,61\% di SMP Hang Tuah Kotabumi pada kriteria "Sangat menarik" dan dikatagorikan sangat layak untuk digunakan. LCDS ini dapat digunakan, baik secara mandiri maupun kelompok, dan dapat dioperasikan pada laptop ataupun komputer PC yang telah terinstal dengan aplikasi microsoft silverlight untuk memudahkan pengoperasian. E-Learning yang dihasilkan LCDS akan lebih menarik apabila di tunjang oleh aplikasi lain yang dapat menampilkan text dan gambar yang kemudian digunakan sebagai bahan dalam pembuatan modul interaktif pada LCDS.

Pendidik diharapkan dapat memanfaatkan kemajuan teknologi dan infromasi sebagai alat untuk membuat media pembelajaran yang menarik dan sesuai dengan kebutuhan peserta didik. Dengan media yang menarik dan sesuai dengan kebutuhan peserta didik, maka diharapkan peserta didik dapat lebih mudah memahami materi pembelajaran dan membuat peserta didik tidak mudah bosan. Harapannya untuk peneliti selanjutnya dapat mengembangkan e-learningl matematika melalui modul interaktif dengan 
Rodiawati, H., \& Komarudin, K. (2018). PENGEMBANGAN E-LEARNING MELALUI MODUL INTERAKTIF BERBASIS LEARNING CONTENT DEVELOPMENT SYSTEM. Jurnal Tatsqif, 16(2). Retrieved from http://journal.uinmataram.ac.id/index.php/tatsqif/article/view/190

menggunakan LCDS ini dengan desain yang berbeda dan dipadukan dengan software pendukung lainnya yang berbeda dengan yang sudah ada.

\section{DAFTAR PUSTAKA}

Aremu, Ayotola, and Bamidele Michael Efuwape. 2013. "A Microsoft Learning Content Development System ( LCDS ) Based Learning Package for Electrical and Electronics Technology-Issues on Acceptability and Usability in Nigeria." American Journal of Research 1 (2):41-48.

Arikunto, Suharsimi. Prosedur Penelitian Suatu Pendekatan Praktik. Jakarta: Rineka Cipta, 1996

Deny Kurniawan, Agus Suyatna, Wayan Suana. 2014. "Pengembangan Modul Interaktif Menggunakan Learning Content Development System Pada Materi Listrik Dinamis." Jurnal Pembelajaran Fisika 3 (1):1-10.

Komala Sari, Fiska, Farida, dan Muhamad Syazali. "Pengembangan Media Pembelajaran (Modul) Berbantuan Geogebra Pokok Bahasan Turunan." Al-Jabar: Jurnal Pendidikan Matematika 7, no. 2 (2016): 135-51

Masykur, Rubhan, Nofrizal, dan Muhammad Syazali. "Pengembangan Media Pembelajaran Matematika dengan Macromedia Flash." Al-Jabar : Jurnal Pendidikan Matematika 8, no. 2 (18 Desember 2017): 177-86.

Mujib dan Mardiyah. "Kemampuan Berpikir Kritis Matematis Berdasarkan Kecerdasan Multiple Intelligences." Al-Jabar: Jurnal Pendidikan Matematika 8, no. 2 (25 Desember 2017): 187-96.

Putrawangsa, S., \& Hasanah, U. (2018). INTEGRASI TEKNOLOGI DIGITAL DALAM PEMBELAJARAN DI ERA INDUSTRI 4.0. Jurnal Tatsqif, 16(1), 4254. Retrieved from http://journal.uinmataram.ac.id/index.php/ tatsqif/article/view/203

Rahmawati, Nurina Kurniasari. "Implementasi Teams Games Tournaments Dan Number Head Together Ditinjau Dari Kemampuan Penalaran Matematis." Al-Jabar: Jurnal Pendidikan Matematika 8, no. 2 (18 Desember 2017): 121-34.

Reny, Eka, Yohanes, dan Dwi Teguh. "Pengembangan Media Pembelajaran Fisika Menggunakan Macromedia Flash Pro 8 Pada Pokok Bahasan Suhu dan Kalor."Jurnal Pendidikan Fisika 1, no. 1 (2013): 1-144

Sugiyono. Metode Penelitian Pendidikan. Bandung: Alfabeta, 2014

Viajayani, Eka Reny, Yohanes Radiyono and Dwi Teguh Rahardjo. 2013. "Pengembangan Media Pembelajaran Fisika Menggunakan Macromedia Flash Pro 8 Pada Pokok Bahasan Suhu dan Kalor." Jurnal Pendidikan Fisika 1 (1):144155. 